\title{
Pathopsychophysiological mechanism of low academic performance among drinkers
}

\author{
Menizibeya Welcome Osain*, Vladimir Pereverzev Alekseevic \\ From $1^{\text {st }}$ International Congress on Neurobiology and Clinical Psychopharmacology and European \\ Psychiatric Association Conference on Treatment Guidance \\ Thessaloniki, Greece. 19-22 November 2009
}

\section{Background}

How alcohol use affect academic performance of students is not fully understood. It was recently shown that alcohol use reduces academic performance of university students by $6.6-12.1 \%$ [1]. But, in spite of the enormous epidemiological data regarding students' problem drinking, the fact that alcohol use leads to a decrease in academic performance remains disputable. This study considers several data that have helped us unravel this disbelief.

\section{Materials and methods}

Peer reviewed publications from Elsevier, Medline and African Index Medicus from 1930 to June 30th, 2009 on the effect of alcohol use on academic performance, cognitive functions and metabolism were critically analyzed. Our data (based on the psychophysiological functions of university students for a three years period of study and follow-up) were examined. We produced a system of academic performance: the psychophysiological concept of academic performance, where the major components motivational and demotivational factors are located in a center of cognition and metabolic balance.

\section{Results}

Distortment of the major elements of the system of academic performance like cognition and a negative shift in metabolic balance can result in low academic performance. A metabolic shift in important substrates (like glucose) for brain functions affects the equilibrium state of this system. This is because cognitive functions are dependent on the blood-brain glucose control systems [2-4]. Alcohol use can affect the metabolic equilibrium state of the system in a drinker, subsequently

Department of Human Physiology, Belarusian State Medical University, Minsk, Belarus leading to a distortment of cognition (a central component of the system). This distortment however, can be modulated by motivational or demotivational factors. The strength of the modulating factors (genetic, metabolic counter-regulatory systems, environmental factors) determines the level of academic performance.

\section{Conclusions}

This study solves the question: If alcohol use leads to low academic performance; can't poor academic performance result in alcohol use? A full understanding of the effect of alcohol use on academic performance lies on the psycho-physiological system of academic performance.

\section{Published: 22 April 2010}

\section{References}

1. Welcome MO, Razvodovsky YE, Dotsenko EA, Pereverzev VA: Prevalence of alcohol-linked problems among Nigerian students in Minsk, Belarus and their academic performance. Pîrt Harcourt Med J 2008, 3(2):120-129.

2. Peters A, Schweiger U, Pellerin L, Hubold C, Oltmanns KM, Conrad M, Schultes B, Born J, Fehm HL: The selfish brain: competition for energy resources. Neurosci Biobehav Rev 2004, 28:143-180.

3. de Galan E, Schouwenberg BJJW, Tack CJ, Smits P: Pathophysiology of management of recurrent hypoglycemia and hypoglycemia unawareness. Neth J Med 2006, 64(8):269-279.

4. Krebs HA, Freedland RA, Hems R, Stubbs M: Inhibition of hepatic gluconeogenesis by ethanol. Biochem J 1969, 112:117-124.

doi:10.1186/1744-859X-9-S1-S234

Cite this article as: Osain and Alekseevic: Pathopsychophysiological mechanism of low academic performance among drinkers. Annals of General Psychiatry 2010 9(Suppl 1):S234. 